\title{
Examining the Efficacy of Fishbowl Simulation in Preparing to Teach English Learners in Secondary Schools
}

\author{
Kimy Liu* and Jon McFarland \\ Department of Teacher Education, California State University Stanislaus, Turlock, CA, United States
}

During the COVID-19 crisis, teacher educators grappled to provide teacher candidates meaningful field experiences to serve English learners (ELs) during campus closures. The purpose of this study was to explore teacher candidates' (TCS) beliefs on second language acquisition (SLA) in the context of teaching ELs in secondary schools. Multiple data sources were used to evaluate fishbowl simulations' efficacy as a viable alternative to gain meaningful field experience. Findings suggest strong connections between participants' beliefs and their chosen instructional moves, with participants realizing the importance of meaning-making. Teacher candidates and teacher educators gain unique insight on

OPEN ACCESS

Edited by:

Manpreet Kaur Bagga,

Partap College of Education, India

Reviewed by:

Balwant Singh,

Partap College of Education, India

Nathalie Sandra Reid,

University of Regina, Canada

*Correspondence:

Kimy Liu

kliu2@csustan.edu

Specialty section:

This article was submitted to

Teacher Education,

a section of the journal

Frontiers in Education

Received: 25 April 2021

Accepted: 14 June 2021

Published: 25 June 2021

Citation:

Liu K and McFarland J (2021) Examining the Efficacy of Fishbowl Simulation in Preparing to Teach

English Learners in

Secondary Schools.

Front. Educ. 6:700051.

doi: 10.3389/feduc.2021.700051 effectively teaching and implementing SLA strategies with fishbowl simulations.

Keywords: teacher candidates, English learners, secondary schools, educational simulation, second language acquisition, coaching (performance)

\section{INTRODUCTION}

According to the NAEP Report Card published by the National Center for Educational Statistics (2020), the achievement gaps between English learners (ELs) and non-ELs in the United States have remained stable over the years. For example, since 2002, 68-74\% of ELs' reading scores in Grade 8 were at or below Basic levels. By contrast, 20-25\% of non-ELs' reading scores in the same grade were at or below Basic levels. For these ELs, robust generic instruction is necessary but not sufficient to support their academic learning needs. All teachers must acquire professional knowledge and teaching strategies to address the learning barriers that are related to ELs' English language development and their struggles of accessing the content of instruction delivered via academic language. Supporting teacher candidates to develop the competency of teaching ELs is imperative for teacher preparation programs.

Equally important, teacher educators and teacher candidates (TC) need to join in the collective reflection on their perception of ELs and the persistent achievement gaps between ELs and non-ELs. Based on their personal experience or the empirical evidence such as data from the National Assessment of Educational Progress (NAEP) Reading Report Card, some teachers might believe it is expected that ELs' educational performances would lag behind their English-only peers. Subsequently, teachers might adopt a deficit perspective of their ELs' educational outlook, lower the standards, or adjust their expectations of ELs' ability based on their performance. Teachers might also formulate their own assumptions on these ELs' motivation, engagement, and capabilities based on their beliefs or interaction with ELs.

Research shows ELs, many of whom are students of color, are negatively impacted disproportionately by poor-quality instruction than their English-only counterparts (Public 
Policy of California, 2020). California has the highest percentage of ELs in the United States, with over 18\% of the total student population identified (California Department of Education, 2020). Additionally, California's EL student population statistically represents socioeconomically disadvantaged families that hover below the poverty level (Public Policy of California, 2020) and suffer from intersectional disadvantages. Teacher preparation programs in California public universities must bear the responsibility to educate upcoming TCs to teach ELs in their communities effectively.

COVID-19 has presented additional barriers in receiving meaningful learning for ELs and TCs who are about to instruct them. The national stay-at-home orders and campus closures due to COVID-19 increased the lurking achievement gap and digital divide for ELs whose familial resources were already lacking (Sawchuk, 2020; Watson and Rosenhall, 2020). These events blocked TCs from completing student teaching face-toface. California schools continued to implement distance learning throughout the 2020-2021 academic year; however, the question remained how teacher preparation programs could support TCs to gain meaningful field experience or to provide an alternative experience during campus closures when the interactions with $\mathrm{K}$ 12 students were extremely limited. EL-related field experience is designed to provide time and space for TCs to 1) learn to observe ELs' behaviors in academic learning, 2) evaluate or assess ELs' learning outcomes, 3) practice general and content pedagogy acquired in method classes, and 4) confirm or confront their educational beliefs and teaching philosophies based on their interactions with ELs in class. Given the constraints of campus closures during the 2020-2021 academic school year and moving traditional face-to-face (F2F) instruction to virtual learning or some hybrid model, teacher educators needed to provide TCs with different teaching-learning experiences to supplement the diminished quantity and quality of meaningful field experience.

Moreover, teacher educators need to help their TCs address the needs of their ELs in in-person, virtual, or hybrid educational environments. Teaching simulations have become increasingly popular as a viable pedagogical method that affords TCs essential learning experiences that mimic real-world application in a lowstakes setting (Bautista and Boone, 2015). Teaching simulations can be used to field test a selected teaching approach in isolation or in context. Video recordings of these educational simulations allow TCs to observe their interactions with simulated students, which provide them context when unpacking their thought processes before, during, and after enacting a lesson plan.

As teacher educators, we answered the call to re-imagine teacher education and to confront challenges associated with the impact of COVID-19 on K-12 schools. We chose to augment our training of teaching TCs to instruct ELs better. We committed to creating a learning activity in the methods course to supplement the TCs' clinical experience. The purpose of this paper is to explore if the use of fishbowl simulations is a viable alternative to provide teacher candidates meaningful field experience in serving diverse English learners in K-12 schools. In this study, we explored two research questions:
- How do teacher candidates' beliefs regarding second language acquisition (SLA) influence their ability to support ELs?

- How effective are fishbowl simulations as a coaching strategy in preparing teacher candidates to teach ELs in their content area in secondary schools?

\section{LITERATURE REVIEW}

To better understand how TCs' beliefs on SLA may influence their efforts and efficacy in supporting ELs, we conducted a literature review on essential teaching skills, educational simulations, and coaching. This review informed us of the interplay between in-class simulations and TCs' acquisition of pedagogy.

\section{Teacher Education and Clinical Skills}

Teacher educators need to encourage TCs to acquire professional knowledge, clinical skills and become confident and reflective practitioners. Stahl et al. (2016) identify four domains to preparing pre-service teachers to enter the profession with confidence by: 1) acquiring and practicing content knowledge and pedagogy; 2) honing practical skills to enact pedagogical theory; 3) becoming reflective practitioners; and 4) developing dispositions for career-long professional learning and addressing these domains requires thoughtfully engineering learning experiences which are rich with opportunities to engage TCs in authentic learning. These experiences also promote metacognition and self-reflection to develop the agency and self-efficacy needed to thrive in the teaching profession.

\section{High-Leverage Practices}

Collaborating with the Council of Exceptional Children (CEC) and CEEDAR Center, McLeskey et al. (2017) have identified 22 HighLeverage Practices (HLPs) for special education teachers. These HLPs are chosen because they have met the following criteria: 1) They are frequently used and often yield positive results in students' learning processes and learning outcomes; 2) these HLPs are identified because these seemingly complex practices can still be taught to novice teachers at a reasonable time span during the teacher preparation program and allow pre-service teachers to achieve an initial proficiency level. These 22 HLPs were grouped into four clusters: collaboration, assessment, socialemotional learning, and instruction. To further promote HLPs, McLeskey et al. (2019) introduced HLPs that can be implemented in an inclusive classroom, using the same conceptual framework. The following instructional HLPs mentioned were particularly relevant to our interests in supporting ELs in an inclusive class that includes: 1) adapting tasks and materials for specific learning goals, 2) teaching cognitive and metacognitive strategies to support learning, 3) providing scaffolded supports, 4) using explicit instruction, 5) using strategies to promote active student engagement, 6) teaching students to maintain and generalize new learning across time and settings, 7) and providing positive and corrective feedback. 


\section{Myths of Second Language Acquisition Instruction}

Teachers should be mindful of the myths and misconceptions about ELs to understand their learning needs (Brown and LarsonHall, 2012). Examples of such myths include, but are not limited to, over-emphasis on the critical period of second language acquisition, stereotypes of the "true bilingual speaker," (p. iv) and overlooking the importance of language comprehension as mentioned in Scarborough. (2001) reading rope model. The myths related to SLA language comprehension can lead to different teaching practices, including underestimating the depth of vocabulary knowledge, discouraging the use of translation as scaffolding for new vocabulary, segregation between English Language Development and learning of content knowledge (Folse, 2004).

Beck et al. (2013) concurred on the importance of robust vocabulary instruction. They cautioned teachers to provide explicit instruction on academic and technical vocabulary as defined in an article by Nation (2001) because novice learners, including ELs, would not be able to master academic vocabulary via incidental learning. In their book, Bringing Words to Life, these authors discussed differences in depth of vocabulary knowledge. Familiarity does not readily lead to mastery or precision of language use. Frequent exposure is necessary but not sufficient for students to learn about using unfamiliar words in a novel context. Novice learners can benefit from questioning, examples, and reasoning to engage in deep learning and cement the connections between the new words and concepts with the pre-existing schemas. Teaching ELs to use language for thinking is the foundation for academic success.

\section{Teacher Perception and Student Performance}

Brophy (1983) discussed self-fulfilling prophecy and teacher expectations. Weinstein et al. (1995) found that teachers' beliefs of students' skill deficits and pessimism about their own teaching efficacy can manifest in fear and vulnerability. However, collaboration with colleagues can generate a sense of empowerment for teaching students with mixed abilities and allow teachers to create alternative interpretations of students' perceived skill deficits. Barton and Coley (2019) discussed the student's learning experience associated with the persistent achievement gaps between minority and low-income students. Multiple studies have confirmed this achievement gap, including the NAEP data, which compares the trend between 2002 and 2019. Classroom diversity is a challenge that all teachers need to embrace if they attempt to meet all students' learning needs. Teachers' background knowledge and life experience shape their perception of students, including ELs. These perceptions contribute to their lens about interpreting the interactions between teaching and learning in the classroom (IRIS Center, 2017). Teachers' perceptions about students often influence their expectations of student learning outcomes as well as students' self-perception of becoming active and effective learners (van den Bergh et al., 2010). Therefore, we should confront these myths mentioned above about teaching ELs and include the study and practice of effective SLA strategies and HLPs in teacher preparation programs.

\section{Educational Simulations}

Teacher educators are challenged with finding new pedagogical strategies to implement with their TCs on addressing the needs of ELs in multiple educational environments. According to (Hartel and Mills, 2002), educational simulations can be used to help students transfer knowledge, develop skills, and improve their proficiency in the application of both knowledge and skills. Educational simulations, such as role-playing, mock trials, and practicing medical procedures on dummies or using simulation machines, have been utilized to provide students with possible experiences in the fields of business (Ben-Zvi, 2010), sales management (Cook and Swift, 2006), law (Douglas and Johnson, 2010), nursing (Jeffries, 2005; Cook et al., 2011), and science (Jones and Laughlin, 2010). Researchers in teacher preparation have also experimented using educational simulations to provide their TCs situated, mirrored incidences that are experienced by educators in the profession (Girod and Girod, 2006, Girod and Girod, 2008; Sawchuk, 2011; Bukko and Liu, 2021). Many educational simulations in the research literature share generalizable characteristics, including their usability in online environments, subject-specific narrowness, and their supplemental use for clinical field practice.

\section{Instructional Coaching}

Simulations are only as good as the feedback students receive from participating in them. Providing a learner-centered experience with scaffolded support can help TCs to connect theory to practice in a safe environment before entering the teaching profession (Polly and Hannafin, 2011). According to Hattie and Timperley (2007), feedback can reduce the discrepancy between what a learner understands and the learning goal. Coaching is critical because it offers the participants affirmative and critical feedback on their progress through the simulation.

Research on coaching has shown to be beneficial for those on the receiving end when coaching methods are applied in a constructive manner that promotes positive reinforcement of effective practice while encouraging corrective practice with low affectivity. Coaching during teaching-learning rehearsals provides TCs structured support as they learn to translate theory into practice (Husbye et al., 2018). When supported by coaching and feedback from experienced practitioners, TCs become more aware of their pedagogical strengths and weaknesses (Stahl et al., 2016; Won et al., 2019; Bukko and Liu, 2021).

\section{METHODS}

This critical action research depicted two purposefully selected cases in the fishbowl simulations. We used Yin (2014) case study approach to examine two representative examples from multiple perspectives. With this case study approach, we used triangulation of multiple data to seek emerging findings. As action researchers, we took advantage of our familiarity of the context and conducted action research within our own classes to examine our own efficacy in preparing TCs to teach ELs. The validity of this action research is grounded in its replicability of 
methods, in other words, if another researcher follows the same protocols, they can also discover the findings that are applicable to their contexts (Duesbery and Twyman, 2019).

In this study, fishbowl simulations are defined as a series of active educational simulations. Participants were assigned the roles of teacher or student when they were "in the fishbowl." Participants were assigned the role of designated observers when they were "outside of the fishbowl." The coaches (i.e., authors) could call "time-outs" to provide in-the-moment coaching when the "teacher" exhibited signs of struggle to implement second language acquisition (SLA) strategies in the simulation. Additional coaching was provided during the intermission of the simulation, and the coach would invite designated observers to provide "teacher" feedback about their teaching.

\section{Participants}

The participating TCs were chosen because they were completing their student teaching in secondary Integrated Science but had different stances on how to teach ELs. Both TCs were in the same cohort of the Single Subject Credential Program. We compared and contrasted these two participants to gain unique insight into augmenting our methods class regarding teaching ELs contentspecific subjects in a secondary class. Rick and Michaela were given pseudonyms to safeguard their identities.

Rick, a Caucasian male, admitted that he was not capable of comfortably using Spanish as an instructional tool, even though he studied some Spanish in high school and college. Michaela, a Hispanic female and former EL herself, comfortably codeswitched between English and Spanish to support Spanishspeaking ELs. Rick taught a Biology course to ninth-graders, and Michaela taught Foundational Science to seventh-graders Both participants conducted their student teaching in person at local public schools in urban areas during the Spring 2020 semester. In this study, we wanted to know if TCs could successfully teach ELs in their content areas via the proxy of fishbowl simulation regardless of their initial beliefs and to further explore the dynamic between TCs' beliefs on teaching ELs and their actions.

\section{Procedure}

We adopted the action research procedure depicted in Bukko and Liu (2021). We utilized the experiential learning model of fishbowl simulations to allow TCs to conduct in-class, practical educational scenarios in which they played the roles of teachers and ELs. Participants were assigned roles where they were either in the inner circle or outer circle. Those in the inner circle played the teacher or student roles. Those in the outer circle played the designated observer role. Different from Bukko and Liu (2021) study, we only focused on two selected cases (Rick and Michaela) for this manuscript.

When Rick and Michaela played the teacher role, they had submitted a proposed lesson plan that they wished to enact in the fishbowl simulation and a learner profile based on an EL they knew or were working with during their field experience. One of the participants in the inner circle of the fishbowl would play the role of the target EL student based on this provided learner profile. TCs took turns playing each role during the fishbowl simulations throughout an eight-week time frame. In the teacher role, candidates submitted a brief lesson plan in advance of what they planned on doing during the timed 20 min simulation. Each candidate was tasked with focusing on SLA strategies to address particular student issues during their fishbowl simulation. Rick and Michaela both focused on eliciting and interpreting students' thinking. They included state standards, lesson objectives, and anticipatory probing questions to engage those simulated students in the fishbowl. Each participant provided an EL profile which included the EL's proficiency levels in the modalities of listening, reading, writing, and speaking. The EL profiles were based on students' English Language Proficiency Assessments for California (ELPAC) test scores and included a brief character bio-based on ELs' interactions with their TCs during previous classes. When acting as designated observers, candidates would take copious notes on the multiple interactions between teacher and students in the fishbowl. They also took note of any suggestions for improvement or modifications made by the coach during coaching sessions.

Intermission and in-the-moment coaching were implemented during each simulation in which candidates received immediate and specific feedback from their classmates and professors (i.e., us as coaches) based on the observations made. All lessons conducted in the fishbowl were timed with $20 \mathrm{~min}$ total. Intermission coaching consisted of specific recommendations for improvement when working with targeted ELs by suggesting various SLA strategies that could be implemented for improved student engagement and increased comprehension of the subject matter. In-the-moment coaching consisted of the coach making real-time targeted corrections for the "teacher" during the lesson. Lesson time was paused during these corrections and resumed afterward so that each TC had an equal amount of time in the simulation.

The onset of the COVID-19 pandemic interrupted in-person fishbowl simulations, thereby forcing several TCs to adjust their lessons to teach in an online environment via video conferencing. Rick's simulation was face-to-face (F2F), and Michaela's was conducted online via Zoom. During Rick's in-person simulation, "students" in the fishbowl were set in a semi-circle facing the "teacher," who used a PowerPoint for a presentational tool and supplemented with paper handouts including a graphic organizer for note-taking. During her online simulation, Michaela utilized the software tools to facilitate the lesson in a fishbowl-like manner by having "students" display cameras while all other observers outside the fishbowl were muted and did not display cameras. She shared her PowerPoint with the "students" and had them interact with her presentational content via Pear Deck to conduct embedded formative assessments in real-time during the presentation.

\section{Data Sources and Data Analysis}

Multiple forms of data were collected, including video recordings of in-class fishbowl simulations, transcripts of video recordings, participant-generated lesson plans, EL student profiles, participants' focused observations and debriefing, participants' self-reflections, and follow-up interviews. These data were used to examine the relationship between participants' beliefs and their 
actions regarding SLA instruction in K-12 settings. Within each case, the proposed lesson plan and EL profile provided insight about the TC's belief and assumption about how to teach a lesson with particular students in mind. The video recording of the teaching demonstration captured the TC's performance and their responses to the feedback from peers and coach. The TC's written critical reflection which was based on their own teaching video provided a balcony view through which the TC examined their teaching and learning experiences. In this study, TCs experienced the simulations from the perspectives of teacher, student, and observer. Processing this information in multiple perspectives could give TCs different insights in this teaching-learning experience. Collaborative coding was conducted to discover emergent themes throughout the study (Strauss and Corbin, 1998; Charmaz, 2014). We also engaged in synchronous and asynchronous discussions via Zoom meetings, exchanged messages about our interpretations of findings, and distilled the lessons learned and used them to our own teaching practices.

\section{Limitations}

Each teaching enactment is a snapshot of a complete lesson. The embedded coaching and reflections are grounded in these snapshots and do not reflect the full scope of participants' content knowledge, clinical skills in teaching, and self-efficacy. As mentioned earlier, the COVID-19 pandemic had interrupted the study, forcing about half of the class to conduct their fishbowl simulations online, which proved quite challenging for some TCs who had originally planned to conduct their lessons in person. Although this did not seem to impact Michaela personally during her fishbowl simulation, we should be mindful that when a TC is required to perform using a foreign platform, they might not perform at their optimal level. We should also be mindful that student-teacher interactions in the faceto-face and virtual environments would be different.

\section{RESULTS}

The results of this study are organized into two sections. Response to coaching results was derived from analysis of the simulation transcripts and videos. Reflection results emerged from the analysis of debriefing, interviews, and participants' written reflections. Their proposed lesson outlines and EL profiles provided insight into their pre-existing perceptions about ELs and their ability to engage learning in the content areas. Their approaches to teaching ELs might or might not be congruent with their pre-stated beliefs. Their critical reflections served as evidence of their responses to coaching and self-reflection on their own perceptions of working with ELs after they had watched their own teaching videos. We conducted the follow-up interviews to gain clarification on their critical reflections as a means of member checking. We analyzed these cases to address our two research questions.

\section{Rick's Simulation Environment and Experience}

Rick's objective for the fishbowl simulation lesson was to have students be able to model protein synthesis by analyzing an
mRNA sequence. In his proposed lesson outline, Rick expressed that he would utilize particular SLA strategies, including modeling, focused pair discussion, and guided notetaking using a $\mathrm{T}$-chart graphic organizer. In his critical reflection, Rick mentioned that he had not learned of the peer-provided EL profile for the student in his fishbowl simulation prior to the lesson but felt confident that his plan was well-prepared, including proper scaffolds to address most EL needs. $\mathrm{He}$ discussed the reality of teachers who received students midsemester:

Going into my lesson that day I did not know what type of student would be my focus [targeted EL]. I received the information right before class and had to adapt quickly. This is true in real life. Over the winter break, I received close to 10 new students spread out in three classes. Of course, none were at the same [English proficiency] level.

For Rick's simulation, another TC played a specific EL profile that was previously posted on the class learning management system's discussion forum. However, Rick admitted that he had not viewed the EL information before conducting his simulation. Rick recognized that teachers need to adapt their instruction in the moment because unplanned interruption is a reality for many K-12 teachers. Rick had started his simulated lesson shortly after finding out the needs of the target EL. This forced Rick to be keenly aware of how the targeted EL engaged with him and the content, as well as interacted with other students in the fishbowl simulation.

Fishbowl simulations can help TCs prepare for unanticipated interruptions to their lessons. On the day of Rick's fishbowl simulation, the class met in a different classroom at a local elementary school rather than at the original high school class setting he was expecting. His original thought of using the whiteboard and teaching from the front of the class was derailed by the home teacher's complete coverage of the whiteboard with notes, dates, and class-reminders. Rick was also unable to access the teacher's computer and projection system. To adapt to this new environment and conduct his teaching demonstration in the fishbowl, Rick started his lesson seated with students in a semi-circle to be able to connect to them more closely. He began the lesson by introducing the objective to the students and used probing questions about the tiered academic vocabulary on his handout that he used to guide students in note-taking by modeling what sections they were working on. While he tried to incite critical thinking of contentspecific key vocabulary words used on his graphic organizer, he often ended up answering his own questions by providing explanations, synonyms, and definitions of the key terms. His teaching approach aimed to help simplify the vocabulary used in the objective and demystify the complexity of new content.

During the intermission, Rick found out more about the profile of his targeted EL in the fishbowl. She was a native Spanish speaker with a rudimentary grasp of academic vocabulary in all modalities of learning. She was quiet and tended to rely heavily on other students around her to follow 
class instruction without understanding where the lesson was going. Rick said that his next steps were to engage this EL more directly without assuming that she understood his directions the first time. The coach encouraged Rick to promote pair-share discussion in Spanish between her and another bilingual student with a shared first language (L1) next to her. The foci of coaching were to get the targeted EL to feel more comfortable discussing the content and for Rick to be more intentional with his use of body language to increase the effectiveness of his modeling.

When introducing two unfamiliar key vocabulary words: "transcribing" and "translating" in biology, Rick employed the analogy of baking cookies to get students more engaged with understanding the process of transcribing an mRNA sequence and translating it into a protein. As soon as he asked, "How many of you like cookies?" Rick noticed that he had peaked their interests with background knowledge shared amongst all students in the fishbowl. During the intermission debriefing, the coach and designated observers recommended that Rick dive deeper with his questions about cookies in order to continue pursuing that line of inquiry and create associative connections to the content in his lesson. During the second half of the simulation, Rick continued to use the cookie analogy as a way to have students associate cookie ingredients with an mRNA sequence by having students draw and complete a Venn diagram to visualize the working pieces in each. However, the evidence showed that 20 min was not sufficient for all students, especially novice learners, to comprehend the difference between transcribing and translating.

\section{Rick's Critical Reflection}

In his critical reflection and follow-up interview, Rick shared several key takeaways from his experiences with fishbowl simulations and his current work with ELs. Rick acknowledged that it was difficult to be videotaped. Although he wanted to know what he could do to improve his teaching, it was not easy to watch himself teach. As an exercise in selfreflection, Rick noticed that he lacked eye contact with the students while teaching during the first half of his simulation. During intermission, the coach and designated observers brought this to his attention, and he was able to improve that element of his lesson.

Rick recognized the difficulty of using analogies, stories, and students' funds of knowledge to create relevance in his science classes. He stated

"I struggle with that because science in general and bringing relevancy to students' funds of knowledge is sometimes really easy and sometimes really hard [...] The biggest thing is I try to pull from where we are in our area. There is a lot of farming here and a lot of students work on a farm, so we can talk about the water cycle and droughts. [...] It comes down to knowing your kids and what they enjoy."

Rick continued to say that he liked to use cooking and sports analogies with his students to explain particular scientific concepts, yet not all curricular concepts readily led to relatable real-life examples. He understood the importance of getting to know his students and being able to incorporate their interests and background knowledge into the lesson's anticipatory sets and ongoing activities to better engage students in his science curriculum. Creating student relevance through curricular content remains an ongoing challenge.

Another significant topic of discussion that arose during Rick's follow-up interview was his strategies for increasing oral participation for his ELs. Having around 40 ELs of different English proficiency levels strewn throughout three classes, Rick struggled to get his ELs to participate orally in class. He tended to focus on partner discussions and group work which aimed to promote impromptu oral presentations. Since he believed that for students to actively engage in his content with one another and practice using the academic vocabulary, they must learn to speak more. In his follow-up interview, Rick stated that using multiple modalities to present information might be a feasible approach to accomplish this goal.

The use of fishbowl simulations also reinforced Rick's need for intentional body language. He received constructive feedback that not only allowed him to promote oral skills with reluctant ELs but it afforded him opportunities to re-imagine his student interaction by working closely with students who reacted positively to closer proxemic engagement.

With regard to his efficacy as a teacher after preparing for, taking part in, and being coached during fishbowl simulations, Rick felt he was more equipped to bolster SLA strategies that enhance student academic achievement. Overall, Rick appreciated the whole process of not only teaching in the fishbowl but "liked viewing other teaching habits [and] seeing other teaching styles" of his classmates. He later stated,

"It was reassuring when they [teacher in fishbowl], not did something wrong, but probably was not a best practice, and in the back of my mind, I would say, 'They probably should have done something like this.' When you [the coach] or others in the class would say that they should have done something like this, I would be like, 'Yes, that's right. We should do that."'

Rick's comment above alluded to how the designated observer role helped him develop a critical eye for identifying negative examples of best practices and generate alternative solutions. These key opportunities in and out of the fishbowl allowed Rick to bridge his own study of impactful pedagogy and the strategic implementation of SLA strategies in context.

\section{Michaela's Simulation Environment and Experience}

When Michaela was scheduled to conduct her teaching demo in the fishbowl simulation, the university and all secondary schools had closed their doors to in-person learning due to the COVID19 pandemic and resorted to virtual instruction. This dramatic change in the instructional environment had greatly affected many K-12 educators at first who were unfamiliar with online instruction and learning or lacked sufficient technology savvy and digital skills to seamlessly conduct class in virtual environments. 
To assist TCs with this shift in the teaching environment, as course instructors, we provided ample support and tech tools to assist TCs to migrate to and practice their own teaching in the online environment. This support included providing access to Zoom accounts, instructional videos that address online instruction and learning and allow for multiple opportunities during class to practice working with online engagement tools. For Michaela's online teaching demo, she utilized the video conferencing application Zoom. To eliminate any confusion of who the simulated students in the fishbowl were, all designated observers muted themselves and did not display video. Only those in the fishbowl were visible while Michaela taught the lesson.

Michaela's lesson simulated a 7th-grade Integrated Science class. She began her fishbowl simulation by taking students' inventory of their access to her presentation using Nearpod and their ability to manage the technology by having them check their volume. Her objective for the lesson was to have students differentiate between three types of rocks. She verbally stated and displayed the lesson objective on every single slide of her presentation.

Knowing that she had a native Spanish-speaking EL who spoke little English in the fishbowl, she then provided the objective in fluent Spanish. Continuing with her objective, Michaela anticipated that students might not understand the word differentiate and asked them to explain it in their own words. After a student offered an appropriate answer, she extrapolated on the student's response by providing other similar words such as different and difference to get students to notice the base differ-to help ignite linguistic connections to other words in English.

During her lesson, Michaela utilized several SLA strategies that not only benefited her ELs but all students in the fishbowl. When introducing the various types of rocks, Michaela had students repeat the words after her to practice their pronunciation of the academic vocabulary. This emphasized her multi-modal approach to instruction that included students interacting with the academic content through reading, listening, writing, and speaking. When introducing igneous rocks to the students, Michaela intentionally presented the Latin root ignis-from the singular ignem-which stands for "fire." This deconstruction and explanation of the term igneous, in turn, made more sense when she explained that these rocks are created out of magma and lava.

Michaela's target EL in the fishbowl was a native Spanish speaker who had an emerging understanding of English and was not comfortable speaking English out loud. To help this EL practice the academic vocabulary in English, she addressed him in Spanish and prepared him to answer in English when called upon. This strategy reduced the affective filter for the EL and allowed him to actively take part in verbally responding to the teacher's probing questions. This method reinforced the EL's accountability for learning the material in English, increased his active usage of the academic vocabulary, and helped establish needed linguistic support in English for struggling students in the online environment.

Michaela's use of assistive technology (i.e., Nearpod) also allowed her to chunk the content into smaller and more manageable bits with interactive checks for understanding that required students to answer written questions about the material she had previously presented. After her presentation and explanation of igneous rocks, she asked all students to provide a written answer to the question, "What layer of the Earth does igneous rocks come from?" which would appear on the shared screen in live time. She continued to guide students' academic language development by requiring them to answer in complete sentences. She also provided a sentence frame in both English and Spanish that her targeted EL and other struggling students could use to start their answers.

Michaela did not receive any in-the-moment coaching during her simulation. She received multiple encouraging feedback during the intermission from her peers and coaches. Such feedback included her realistic understanding of ELs' needs and the targeted support provided to address those needs. She was also praised for keeping high standards for all students, including ELs, and for promoting student accountability and their use of academic language.

\section{Michaela's Critical Reflection}

During Michaela's follow-up interview, we explored several aspects of her critical reflection and further clarified her perceptions of working with ELs. This included her use of assistive technology, pedagogical approach to teaching ELs, and her rationale behind her chosen instructional approaches. Additionally, we discussed her thoughts on her fishbowl experience and how coaching influenced her future practice.

She realized that the use of assistive technology such as Google Translate and Read \& Write Gold software helped students translate their digital content from the second language being English (L2) to the L1 and vice versa without being burdened to do it herself. These supplemental applications saved her time in the preparation of her lessons. Understanding how these tech tools assisted her students' meaning-making, she digitized her content to make it accessible to all students. She thoroughly utilized the school's Google Classroom learning management system to house her content in an organized fashion, allowing students to practice and review content with little scaffolding.

The fishbowl simulation experience resonated with Michaela because of the similarity between the simulation and her actual class. In her classes, Michaela had approximately 50 ELs in her 7 th grade Earth Science classes combined, with about $90 \%$ of them being Spanish speakers. According to Michaela, switching to the shared L1, Spanish, was an intentional and appropriate choice. She explained that she often used code-switching as a teaching approach to support ELs that emerged from her experience as an EL growing up. In her classes, she seamlessly toggles between instruction in English and Spanish. Michaela also promotes student-to-student interaction in their shared L1, which helps them process her science content (i.e., input) and promotes verbal or written production (i.e., output) in English (L2).

According to Michaela, she applied her life experience as an EL in constructing an authentic composite learner profile. Michaela's only exposure to English was in school growing up because her parents were Spanish-only speakers. She had learned to anticipate ELs' misunderstandings based on her own experiences as a quiet 
kid who dared not speak up in class when she did not understand the content. This inspired Michaela to address the targeted EL's unique learning needs in the fishbowl. She recognized the effectiveness of certain SLA strategies because they were used and proven effective with her as both student and teacher. Examples of such approaches include slowed speech, intentional repetition of key vocabulary words, and additional guided practice. She also employed total physical response by increasing the use of body language and exaggerating facial expressions to augment the effectiveness of her communication with students about unfamiliar concepts and vocabulary.

During her follow-up interview, Michaela had expressed a unique insight into how to teach ELs. She extrapolated from her personal experience, which emphasized the importance of word study and grammar. She taught students how to deconstruct unknown words by analyzing word prefixes, suffixes, and bases to help students make educated guesses that supported students to make linguistic connections between English and their respective L1. She relied heavily on her own fluency in Spanish to apply and highlight cognates in both English and Spanish whenever possible to reduce the cognitive load of unknown words in English for ELs. These strategies empower ELs by encouraging them to tap into their linguistic funds of knowledge, which make learning new content more accessible and relatable.

\section{DISCUSSION/SIGNIFICANCE}

We purposefully organized the following discussion section into four parts to appropriately address the two research questions. These sections were placed under the subheadings: from beliefs to actions, responses to coaching, critical reflections, and importance of sense-making.

\section{From Beliefs to Actions}

When reflecting on their fishbowl experiences, TCs learned that mistakes are not seen as an indication of failure but as an opportunity for growth. In both cases, teacher beliefs shaped their perceptions and interpretations of students' reactions. TCs' interpretations dictated their choices of approach to help students make sense of the content. Rick believed using visual aids and guided direct instruction were sufficient methods for his ELs, which was where the extent of his support remained. Michaela, on the other hand, recognized nonverbal signs of confusion from students' facial expressions and body language, took a proactive approach to check for understanding throughout the lesson, implemented choral repetition, and retaught the content when needed.

TCs' written reflections revealed the profound impact rehearsal and coaching had on participants' professional growth. Participants demonstrated and articulated the importance of adjusting their pace of teaching and incorporating think-time. They also recognized the importance of actively checking for understanding.

Our TCs recognized the need for good SLA strategies, but they lacked sufficient experience to utilize the necessary strategies at the moment. TCs' effectiveness of SLA strategies depends on their prior beliefs or knowledge and experience linked to their teaching skills. TCs are also influenced by their dispositional stand on the use of SLA strategies. Like Rick and Michaela, many candidates are not comfortable venturing outside of their pedagogical comfort zone to try unfamiliar strategies with students under the condition of high-stake performance assessment (i.e., student teaching). The fishbowl is a time and space for unique learning to occur. In the fishbowl, the simulation norms have been established and honored so that the affective filters have been lowered. Therefore, fishbowl simulations can act as a type of field testing in an environment where safe failure is acceptable and beneficial struggles are encouraged.

During Rick's subsequent post-interview when discussing his limited use of SLA strategies, Rick stated, "I am doing the best I can." While it is plausible that Rick had the best intentions when helping his ELs, this statement highlights his limited understanding of his ELs' learning needs. It also draws attention to his lack of experience and limited capacity to apply SLA strategies to provide a contextual-fit solution for the learning problems. A wide range of teaching simulation examples provided ample opportunities for Rick to learn as a designated observer and come up with viable options for his peers. Rick felt empowered when he wrote down plausible solutions for several scenarios that his classmates could have used during their simulations. Novice teachers need think-time to generate innovative approaches to solve problems. The debriefing and critical reflection embedded in the fishbowl simulations provided a forum for them to engage in this deep processing.

When asked about relevancy and content accessibility, Michaela initially concentrated on seeking solutions using instructional technology (i.e., using Google Translation). Michaela later recognized that while instructional technology can be instrumental for ELs' learning, effective SLA strategies can benefit all learners. Instructional technology is mutually beneficial because ELs can get needed scaffolding on English language development while teachers can focus on teaching content. Michaela might be over-relying on instructional technology because of the convenience, and she might consider integrating other SLA strategies with appropriate technology. Technology should not supplant good teaching.

\section{Response to Coaching}

The findings of this study are aligned with Knowles et al. (2020) adult learning theory. At the onset of the study, both participants stated that they were aware of the challenges of teaching ELs and attempted to provide support to offset the barriers related to what they perceived as the result of limited English proficiency. They were ready and motivated to participate because the lessons learned had a direct impact on their current role as the TC. As adult learners, they value and draw references from direct experience. With coaching, Rick was able to employ some SLA strategies to make the learning relatable with all students, including the targeted EL. His use of graphic organizers and the cookie analogy helped simulated students learn the content vocabulary and novel complex concepts. After receiving feedback from coaches and peers and watching his own teaching video, 
Rick was able to identify the skill he would like to learn most (i.e., how to increase the target EL's oral participation) and possible approaches that could help him achieve this goal. When he received encouraging feedback from his peers on using an analogy to help students engage in the study of biology, his confidence was visibly boosted. When he recognized he could be successful, he accepted the corrective feedback and adjusted his approach of interacting with simulated students. As a result of his changes in teaching behavior by modifying his proximity to students in order to improve learner engagement, simulated students appeared to be more in-tune to his instruction. This unique learning experience allowed Rick to have a deeper understanding of the proposed pedagogy and to have a stronger motivation to implement the SLA proximity strategy in his teaching.

Data derived from the EL learning profiles and subsequent debriefing suggested that participants had different interpretations of the learning needs of ELs. Data provided both participants and researchers insight into TCs' preconceived notions about ELs. In comparison, Michaela had a more realistic view about her simulated EL, which was evidenced by her proposed lesson plan, description of profiles, and her approach to using shared L1 to support her targeted EL and monitor all simulated students' learning.

There was a strong connection between Rick's and Michaela's lived experiences with SLA and their beliefs regarding the needs of ELs. Rick assumed that the use of academic vocabulary displayed on worksheets or PowerPoints would be sufficient support to correctly pronounce the words, develop conceptual understanding, and use them in academic discourses. As for Michaela, she relied on her bilingualism, thinking that student understanding would be achieved with translation alone. During the coaching, both TCs' assumptions were challenged. Rick realized that the visual display of the words alone is not a reliable indicator that students understand the meaning of the words. Michaela recognized the cost-benefit of using L1 extensively in her instruction. The cost was that this approach is extremely time-consuming, and only the learners with shared L1 can benefit from it. As a result of this study, she was able to empathize with teachers who do not share the same L1 with their students.

Effective coaching can reduce the gap between the learner's current level of performance and perceived proficient standards. According to Hattie and Timperley (2007), four types of feedback should be given, which is applicable during the course of face-toface coaching and eCoaching: 1) affirmative or encouraging feedback to specific instructional moves, 2) corrective feedback to identify the errors and provide targeted remedial actions, 3) questioning feedback to get information or seek clarification on the rationale behind a specific instructional move and 4) instructive feedback to provide novice teachers directly to the appropriate next instructional move. As instructors, we noticed that we needed to practice using these four types of feedback in our own teaching, with special emphasis on questioning feedback and instructive feedback. It is important for us to delve deeper into understanding the rationale behind a student's professional judgment so that we can help TCs correct misconceptions. Equally important, in the context of coaching, teacher educators should give TCs instructive feedback on what they should do next.

\section{Critical Reflection}

Rick and Michaela were both aware that they needed to introduce content-specific vocabulary in their instruction. Rick stated that the use of analogies was an effective strategy to help students make connections with Tier 3 words (i.e., content-specific vocabulary), realizing he should not have glossed over Tier 3 multisyllabic words (e.g., transcription) that ELs could not pronounce or understand. Michaela, on the other hand, took a methodical approach to introduce Tier 3 words by having students pronounce them through choral repetition. She also foresaw potential difficulty ELs may have had understanding such technical words and prompted simulated students to notice the prefixes or bases of these words to spark commonalities with other words in their L1 and English. For example, Michaela tried to explain her word association between "ignite" and "igneous" rock but did not realize that ign-was a morpheme her ELs did not recognize. Although Michaela understood that she could take advantage of connections between Spanish cognates and some English words, she could not activate students' prior knowledge if it did not exist. Both participants found their experiences in these simulations beneficial in developing their pedagogical skills and becoming more aware of the possibly overlooked needs of ELs.

The critical reflection and post-interview allowed both Rick and Michaela to express how their perceptions on working with ELs had or had not changed. Both participants expressed that the fishbowl simulation activities and experiences showed them that implementing effective SLA strategies is more difficult than previously thought before taking part in the simulations. While Rick mentioned that his perception of working with ELs did not change much, he realized that educators needed to be aware of the multitudinous languages spoken by ELs in California. He stated, "I think the biggest thing that I keep telling myself is that not all English learners are Spanish speaking. So, the solution isn't to always just offer a Spanish version or to speak Spanish. Many other languages are represented in our area, and we have to plan for them as well." This is an important point to consider since there are 75 different languages spoken by ELs in California (California Department of Education, 2020).

Conversely, Michaela expressed a great change in her perception of working with ELs. While having been a former EL herself, she approached the fishbowl simulations with personal and academic experiences that afforded her a better understanding of how to implement SLA strategies with her ELs, as well as utilize her linguistic background in Spanish to support her ELs who shared the same L1 as her. In her critical reflection, she wrote,

\begin{abstract}
"My perception about English language Learners only got stronger; my main reason I decided to teach was to help those particular students. After seeing how other teachers do not have the advantage of speaking another language besides English, I realized as a teacher we need to develop more English Language learner strategies in our daily lessons. These strategies help not only English learners but also students who are not English learners."
\end{abstract}

Her above response was later discussed in her post-interview, which brought out more revelations for Michaela. She recognized 
that she was one of the very few teacher candidates in the class who could draw from their L1 in Spanish and experiences as a former EL herself to support her Spanish-speaking ELs with content taught fluently in both Spanish and English simultaneously. However, after witnessing other simulated ELs in multiple fishbowl simulations who did not speak Spanish, she felt humbled by her classmates who did not possess the same cultural and linguistic capital as her. When pressed further on her perceptions of working with ELs, she stated, "I knew that I was going to have English learners, but I did not think I was going to have a student whose language I would have no clue how to read or speak." This realization only reinforced her need to apply quality SLA strategies that not only supported ELs' success with academic English but all students in the class.

\section{Importance of Sense-Making}

Learning is a process in which students use assimilation and accommodation to update their pre-existing schemas, include wide-range examples attached to these schemas, and make three types of connections. These connections are tied to their personal experience, to their world knowledge, and to the book knowledge they have acquired. According to Knowles et al. (2020) andragogy or adult learning theory, adult learners learn best when they use a self-directed learning approach, draw knowledge and reference from personal experiences, participate in directional and purposeful learning when they have buy-in and finally when they need to solve a problem. For these adult learners, the purpose of authentic learning is to expand their repertoire of knowledge or skills so that they will be retained in their long-term memory to make sense of future problems.

In this study, we recognized the importance of applying principles of andragogy in teaching TCs about general and content pedagogy. Analysis of the data suggested that both Rick and Michaela were ready and motivated to learn from self-directed approaches, and they were genuinely interested in learning how to apply proven effective SLA strategies because these new skills were relevant to their current roles. With specific and immediate feedback during the lesson demonstrations, novice teachers can make explicit connections between the study of content pedagogy and enactment of the lesson, promote quality language learning, acquire content knowledge through metalinguistic techniques, and bolster transfer (Liu et al., 2016).

Debriefing, critical reflection and follow-up interviews provided the time and space for participants to unpack their learning experiences. In order to retain and develop proficiency in content pedagogy, TCs must engage in active learning to make deep connections between experiential learning and book knowledge (Bukko and Liu, 2021). For example, Rick recognized the utility of using analogy to tap into the funds of knowledge ELs bring to make sense of the unfamiliar concept (i.e., transferring vs. transcribing in DNA replication). $\mathrm{He}$ also noticed how the sense of relevancy and connections to prior knowledge had piqued the interests of his initially nonchalant learners. Michaela also noticed that the power of using a shared L1 could help her ELs have meaningful access to the curriculum, and it also enabled her as a teacher to use probing questions for monitoring students' learning and performance. Guided coaching and simulated experiences combined help TCs deepen their understanding of how to address the needs of ELs. Coaching can help TCs increase metacognition by better recognizing their understanding and misunderstanding of SLA and linguistic transfer. Both participants displayed an emerging understanding of how to help make lessons relevant, purposeful, and meaningful. While helping ELs make sense of their learning, both TCs were empowered by making sense of their own teaching-learning experiences. The process of teaching and learning about the importance of sense-making has bolstered both Rick's and Michaela's self-efficacy as teachers.

\section{Our Own Lesson Learned}

As teacher educators, we also learned from this action research. This study prompted us to explore the connections between TCs' initial beliefs and their approaches about teaching ELs. It is noteworthy that in the context of mini-lessons, there were no paradigm shifts in the TCs' belief systems about how they should teach ELs. But some incremental changes were observed in their final written reflections. Their lessons learned were grounded in their initial beliefs. For example, Rick believed that ELs' active oral participation was a valid and robust indicator for their understanding; therefore, he would actively seek strategies that allowed him to accomplish this teaching goal. Michela believed in her abilities to connect with her ELs because of her lived experience as an English language learner and her shared first language with her students. Consequently, she would use the tools that proved effective for her. She did not consider the factor that her ELs might not speak Spanish. It is our responsibility to teach TCs about expanding their teaching skills that allow ELs different ways other than oral participation to demonstrate their understanding. We also need to teach different second language acquisition strategies (e.g., total physical response, use of manipulatives, etc.) that can benefit students who do not share the same first language with the teacher.

\section{Significance}

Fishbowl stimulations are different from typical lesson demonstrations because TCs can adjust their teaching based on the immediate and specific feedback they received. They also have opportunities to observe the instantaneous change of student's response as a result of their changed teaching approach. TCs appreciate think-time to reflect and revise their own teaching-learning approaches. They can benefit from individualized coaching, including the use of think-aloud in the context of how to make on-the-go instructional decisions and make the invisible learning visible (Liu et al., 2016; Won et al., 2019). This study is important because it provides a platform that shows the power of coaching in terms of helping TCs to engage in instructional High-Leverage Practices that make teachinglearning experiences more inclusive and impactful. McLeskey et al. (2017), McCleskey et al. (2019) identified 22 HLPs for both special education and general education teachers. Evidence from this study concurred with the notion of teaching HLPs to TCs. 
Fishbowl simulations allow TCs to explore how to set and prioritize instructional goals within their mini-lessons, program learning activities toward a specific instructional goal, provide scaffolded support, and teach cognitive and metacognitive strategies to promote active student learning (Bukko and Liu, 2021).

This action research describes an acquisition process of SLA strategies, which meets the optimal learning conditions described in Knowles et al. (2020) adult learning theory. This study provides an alternative or supplemental venue to practice clinical skills before or while interacting with K-12 students. The focus on learner needs and pedagogical skills demonstrated in this study contributes to the development of teacher self-efficacy and provides alternative learning experiences that may supplement and improve current teacher education practices.

\section{DATA AVAILABILITY STATEMENT}

The raw data supporting the conclusion of this article will be made available by the authors, without undue reservation.

\section{REFERENCES}

Barton, P. E., and Coley, R. J. (2009). Those Persistent Gaps. Educ. Leadersh. 67 (4), 18-23.

Bautista, N. U., and Boone, W. J. (2015). Exploring the Impact of TeachME Lab Virtual Classroom Teaching Simulation on Early Childhood Education Majors' Self-Efficacy Beliefs. J. Sci. Teach. Educ. 26 (3), 237-262. doi:10.1007/s10972014-9418-8

Beck, I. L., McKeown, M. G., and Kucan, L. (2013). Bringing Words to Life: Robust Vocabulary Instruction. Guildford Press.

Ben-Zvi, T. (2010). The Efficacy of Business Simulation Games in Creating Decision Support Systems: An Experimental Investigation. Decis. support Syst. 49 (1), 61-69. doi:10.1016/j.dss.2010.01.002

Brophy, J. E. (1983). Research on the Self-Fulfilling Prophecy and Teacher Expectations. J. Edu. Psychol. 75 (5), 631-661. doi:10.1037/0022-0663.75.5.631

Brown, S., and Larson-Hall, J. (2012). Second Language Acquisition Myths: Applying Second Language Research to Classroom Teaching. University of Michigan Press.

Bukko, D., and Liu, K. (2021). Developing Preservice Teachers' Equity Consciousness and Equity Literacy. Front. Educ: Teach. Educ. doi:10.3389/ feduc.2021.586708 Available at: https://www.frontiersin.org/articles/10.3389/ feduc.2021.586708/full

California Department of Education (2020). Facts about English Learners in California - CalEd Facts. Available at: https://www.cde.ca.gov/ds/sd/cb/ cefelfacts.asp (Retrieved June 17, 2021).

Charmaz, K. (2014). Constructing Grounded Theory. 2nd edition. Sage.

Cook, D. A., Hatala, R., Brydges, R., Zendejas, B., Szostek, J. H., Wang, A. T., et al. (2011). Technology-enhanced Simulation for Health Professions Education: A Systematic Review and Meta-Analysis. Jama 306 (9), 978-988. doi:10.1001/ jama.2011.1234

Cook, R. W., and Swift, C. O. (2006). The Pedagogical Efficacy of a Sales Management Simulation. Marketing Educ. Rev. 16 (3), 37-46. doi:10.1080/ 10528008.2006.11488971

Douglas, K., and Johnson, B. (2010). Legal Education and E-Learning: Online Fishbowl Role-Play as a Learning and Teaching Strategy in Legal Skills Development. Elaw J. 17, 28.

Duesbery, L., and Twyman, T. (2019). 100 Questions (And Answers) about Action Research. San Francisco: Sage publishing.

Folse, K. S. (2004). Vocabulary Myths: Applying Secondary Language Research to Classroom Teaching. University of Michigan Press.

\section{ETHICS STATEMENT}

The studies involving human participants were reviewed and approved by the California State University Stanislaus IRB. The patients/participants provided their written informed consent to participate in this study.

\section{AUTHOR CONTRIBUTIONS}

KL contributed to the concept and design of the study. JM organized the database. KL wrote the first draft. Both authors contributed to data analysis, manuscript revision, read, and approved the submitted version.

\section{FUNDING}

This study is funded by California State University Stanislaus Research, Scholarship, Creative Activity (RSCA) Grant for 2019-2020.

Girod, M., and Girod, G. (2006). Exploring the Efficacy of the Cook School District Simulation. J. Teach. Educ. 57 (5), 481-497. doi:10.1177/0022487106293742

Girod, M., and Girod, G. (2008). Simulation and the Need for Practice in Teacher Preparation. J. Tech. Teach. Educ. 16 (3), 307-337.

Hartel, J. P., and Mills, B. J. (2002). Using Simulations to Promote Learning in Higher Education. Sterling, VA: Stylus publishing

Hattie, H., and Timperley, H. (2007). The Power of Feedback. Rev. Educ. Rev. American Educational Research Association 77, 81-112. doi:10.3102/ 00346543029848

Husbye, N. E., Wessel Powell, C., Vander Zanden, S., and Karalis, T. (2018). Coaching in Practice-Based Literacy Education Courses. Read. Teach. 72 (2), 191-200. doi:10.1002/trtr.1692

IRIS Center (2017). Classroom Diversity. Available at: https://iris.peabody. vanderbilt.edu/module/div/cresource/\#content (Retrieved June 17, 2021).

Jeffries, P. R. (2005). A Framework for Designing, Implementing, and Evaluating Simulations Used as Teaching Strategies in Nursing. Nurs. Educ. Perspect. 26 (2), 96-103.

Jones, T. C., and Laughlin, T. F. (2010). PopGen Fishbowl: a Free Online Simulation Model of Microevolutionary Processes. Am. Biol. Teach. 72 (2), 100-103. doi:10.1525/abt.2010.72.2.9

Knowles, M. S., Holton, E. F., III, Swanson, R. A., and Robinson, P. A. (2020). The Adult Learner: The Definitive Classic in Adult Education and Human Resource Development. 9th ed. New York: Routledge. doi:10.4324/9780429299612

Liu, K., Robinson, Q., and Braun-Monegan, J., (2016). Pre-service Teachers Identify Connections between Teaching-Learning and Literacy Strategies. J. Educ. Train. Stud. 4 (8). doi:10.11114/jets.v4i8.1538

McLeskey, J., Berringer, M., Billingsley, B., Brownell, M., Jackson, D., Kennedy, M., et al. (2017). High-leverage Practices in Special Education. Arlington, VA: CEC and CEEDAR Center.

McLeskey, J., MaheadyBillingsley, L. B., BrownellM, T., and Lewis, T. J. (2019). High-leverage Practices for Inclusive Classrooms (New York: Routledge).

Nation, I. S. P. (2001). Learning Vocabulary in Another Language (Cambridge Applied Linguistics). Cambridge: Cambridge University Press. doi:10.1017/ CBO9781139524759

National Center for Education Statistics (2020). NAEP Report Card: reading. National Assessment of Educational Progress. Available at: https://www. nationsreportcard.gov/reading/?grade $=4$ (Retrieved June 10, 2021) and Available at: https://www.nationsreportcard.gov/reading?grade $=8$

Polly, D., and Hannafin, M. J. (2011). Examining How Learner-Centered Professional Development Influences Teachers' Espoused and Enacted Practices. J. Educ. Res. 104 (2), 120-130. doi:10.1080/00220671003636737 
Public Policy of California (2020). California's English Learner Students. Available at: https://www.ppic.org/publication/californias-english-learner-students/\#fn-7

Sawchuk, S. (2020). When Schools Shut Down, We All Lose. Educ. Week. Available at: https://www.edweek.org/leadership/when-schools-shut-down-we-all-lose/ 2020/03

Sawchuk, S. (2011). Simulations helping novices hone skills. Educ. Week 30 (15), 1. Available at: http://www.edweek.org/ew/articles/2011/01/12/15simulate_ep-2. h30.html? qs=simulations

Scarborough, H. S. (2001). "Connecting Early Language and Literacy to Later reading (Dis)abilities: Evidence, Theory, and Practice," in Handbook for Research in Early Literacy. Editors S. Neuman and D. Dickinson (New York, NY: Guilford Press), 97-110.

Stahl, G., Sharplin, E., and Kehrwald, B. (2016). Developing Pre-service Teachers' Confidence: Real-Time Coaching in Teacher Education. Reflective Pract. 17 (6), 724-738. doi:10.1080/14623943.2016.1206882

Strauss, A., and Corbin, J. (1998). Basics of Qualitative Research: Techniques and Procedures for Developing Grounded Theory. 2nd ed. Sage.

van den Bergh, L., Denessen, E., Hornstra, L., Voeten, M., and Holland, R. W. (2010). The Implicit Prejudiced Attitudes of Teachers. Am. Educ. Res. J. 47 (2), 497-527. doi:10.3102/0002831209353594

Watson, A., and Rosenhall, L. (2020). Schools Shut Down in Massive Numbers across California amid Coronavirus Fears. CalMatters. Available at: https:// calmatters.org/projects/schools-shut-down-in-massive-numbers-across-californiaamid-coronavirus-fears/

Weinstein, R. S., Madison, S. M., and Kuklinski, M. R. (1995). Raising Expectations in Schooling: Obstacles and Opportunities for Change. Am. Educ. Res. J. 32 (1), 121-159. doi:10.3102/00028312032001121

Won, N., Liu, K., and Bukko, D. (2019). Developing Instructional Skills: Perspectives of Feedback in Student Teaching. Networks: Online J. Teach. ResearchAn Online J. Teach. Res. 21. doi:10.4148/24706353.1303

Yin, R. K. (2014). Case Study Research: Design and Methods. 6th Ed. Sage.

Conflict of Interest: The authors declare that the research was conducted in the absence of any commercial or financial relationships that could be construed as a potential conflict of interest.

Copyright (c) 2021 Liu and McFarland. This is an open-access article distributed under the terms of the Creative Commons Attribution License (CC BY). The use, distribution or reproduction in other forums is permitted, provided the original author(s) and the copyright owner(s) are credited and that the original publication in this journal is cited, in accordance with accepted academic practice. No use, distribution or reproduction is permitted which does not comply with these terms. 